\title{
Factors impacting postoperative haemorrhage after transnasal endoscopic surgery*
}

\author{
Kanako Akita1,2, Masaki Hayama', Takeshi Tsuda', Yohei Maeda', \\ Hitoshi Akazawa', Ayaka Nakatani', Sho Obata', Kazuya Takeda', \\ Hidenori Inohara
}

Rhinology Online, Vol 3: 141 - 147, 2020

http://doi.org/10.4193/RHINOL/20.059

*Received for publication:

' Department of Otorhinolaryngology-Head and Neck Surgery, Osaka University Graduate School of Medicine, Suita City, Osaka, July 25, 2020

Japan

2 Department of Otolaryngology, Suita City Hospital, Suita City, Osaka, Japan
Accepted: September 15, 2020

Published: September 23, 2020

\begin{abstract}
Background: Transnasal endoscopic surgery (TES) is an established procedure for the treatment of chronic rhinosinusitis, septal deviation, and paranasal benign tumours. Postoperative haemorrhage $(\mathrm{POH})$ is a common complication following TES. Various studies have addressed the risk factors for intraoperative bleeding and the methods to improve the operative field by reducing bleeding. However, the factors affecting POH following TES have not been fully elucidated. Therefore, we aimed investigate the risk factors for $\mathrm{POH}$ following TES.
\end{abstract}

Methodology: We studied 807 patients who underwent TES. The variables between cases with and without $\mathrm{POH}$ were compared using univariate and multivariate models. We also examined the site and timing of bleeding.

Results: $\mathrm{POH}$ was observed in 21 cases (2.6\%). Seven cases required treatment in the operation room (0.9\%). The most common sites of bleeding were around sphenopalatine foramen, and the median time to $\mathrm{POH}$ was the 7 th day after surgery. Multivariate analysis showed that anti-thrombotic medication, low platelet count, and surgical indication for sinonasal tumour were independent risk factors for $\mathrm{POH}$.

Conclusions: $\mathrm{POH}$ after TES is a relatively common complication. Careful intraoperative haemostatic procedures may be required in these cases.

Key words: endoscopic sinus surgery, postoperative haemorrhage, anti-thrombotic medication, sinonasal tumour, low platelet count

\section{Introduction}

Transnasal endoscopic surgery (TES) is an established procedure for the treatment of chronic rhinosinusitis, septal deviation, paranasal cysts, allergic rhinitis, benign tumours, and more ${ }^{(1-6)}$. Postoperative haemorrhage $(\mathrm{POH})$ is a common complication that can occur after any surgery, including TES. Stankiewicz et al. indicated that $\mathrm{POH}$ after endoscopic sinus surgery (ESS) was the most frequent complication ${ }^{(7)}$. Dalziel et al. showed that the median rate of $\mathrm{POH}$ after nasal polyp surgery was $2.5 \%$ $(0.2-21.1 \%)$ in a systematic review ${ }^{(8)}$. Regarding septoplasty, the rate of $\mathrm{POH}$ has been reported to be $0.8-3.0 \%{ }^{(9-11)}$. These results suggest that $\mathrm{POH}$ is a common complication following TES. In recent years, the indication for ESS has expanded beyond chronic sinusitis to include lacrimal and orbital diseases, cranial base diseases, and some malignancies. Therefore, the risk of $\mathrm{POH}$ may be increased.

Intraoperative bleeding interferes with the surgical view, and this may lead to complications. Several solutions have been reported ${ }^{(12-14)}$. However, attention to the subject of $\mathrm{POH}$ following TES has been lacking.

$\mathrm{POH}$ negatively affects quality of life, and readmission or longer hospital stays may be required following $\mathrm{POH}$. In addition, prolongation of postoperative treatment increases healthcare costs. However, the factors impacting $\mathrm{POH}$ following TES have 
not been fully elucidated. Identification of the risk factors for $\mathrm{POH}$ enables better surgical planning and aids in providing an appropriate explanation to patients.

The study aimed to retrospectively investigate $\mathrm{POH}$ in our institute and identify the risk factors for $\mathrm{POH}$.

\section{Materials and methods}

\section{Patients}

This retrospective study was approved by the institutional review board of Osaka University Hospital (\#16329). We included patients who underwent ESS between 2014 and 2018 at the Department of Otorhinolaryngology Head and Neck Surgery, Osaka University Hospital. All patients were followed up for six months. The exclusion criteria included surgery for malignant tumours, skull base surgeries, laser surgery for the treatment of allergic rhinitis, sphenopalatine artery ligation for severe epistaxis, and laser surgery or coblation for hereditary haemorrhagic telangiectasia.

$\mathrm{POH}$ was defined as a haemorrhage requiring haemostatic procedures or surgery, such as gauze packing, mucosal cauterization, or clipping of blood vessels by physicians, within 30 days following surgery. Minor $\mathrm{POH}$ was defined as bleeding that could be stopped in the treatment room or outpatient setting and did not require surgery; major $\mathrm{POH}$ was defined as bleeding that required surgery under local or general anaesthesia.

\section{Site and timing of postoperative haemorrhage}

The bleeding sites were classified as the sphenopalatine foramen areas, middle turbinate, inferior turbinate, nasal septal mucosa, anterior face of sphenoid sinus, ethmoid sinus, and others. The timing of bleeding was divided into 1-3 days, 4-6 days, $7-10$ days, $11-14$ days, and $\geq 15$ days after surgery.

\section{Data collection}

The following preoperative information was collected about the patients: sex, age, body mass index (BMI), blood pressure on admission, haemoglobin $\mathrm{A} 1 \mathrm{c}(\mathrm{HbA} 1 \mathrm{c})$, activated partial thromboplastin time (APTT), prothrombin time/international normalized ratio (PT-INR), platelet count, and anti-thrombotic medications (anti-coagulant or anti-platelet medications). Surgical indication and surgical factors (operation time, type of anaesthesia, and operating procedure) were also extracted. Given that there was an issue with missing data, we analysed $\mathrm{HbA} 1 \mathrm{c}$ in 457 patients.

\section{Statistical analyses}

All statistical analyses were performed using JMP Pro. 14 Software (SAS Institute Inc., Cary, NC, USA). The chi-square test was used to perform univariate analyses. Predictors that were found to be related to $\mathrm{POH}(p \leq 0.20)$ were then entered into a multivariate logistic regression model, using stepwise forward and backward selection. $\mathrm{P}<0.05$ was considered statistically significant.

\section{Results}

Demographics of the cases

We included 807 patients in this study, and their clinical data are presented in Table 1. There were $60.6 \%$ male and $37.4 \%$ female patients, with a median age of 57 years. Forty-four patients (5.5\%) were on internal antithrombotic medication before the surgery. The surgical indications were sinusitis in $51.7 \%$ of patients, nasal septal deviation in $10.9 \%$, benign tumour in $9.9 \%$, paranasal cyst in $9.5 \%$, allergic rhinitis in $5.6 \%$, fungus ball in $3.8 \%$, and other sinus diseases in $8.6 \%$. In addition, $80.7 \%$, $49.6 \%$, and $36.8 \%$ of patients had ESS, septoplasty, and submucosal resection of the inferior turbinectomy, respectively. Among the various diseases, patients with chronic rhinosinusitis had the highest number of cases of postoperative bleeding at 2.2\%, while patients with benign tumours had the highest frequency of postoperative bleeding at $6.3 \%$ (Table 2).

The major bleeding commonly occurred after the 7th postoperative day

$\mathrm{POH}$ was observed in 21 of 806 patients (2.6\%; Table 1). The percentage of patients requiring treatment for $\mathrm{POH}$ in the operating room (major bleeding) was $0.9 \%$. The 21 cases of $\mathrm{POH}$ included 9 cases of chronic rhinosinusitis, 5 cases of paranasal benign tumour, 4 cases of paranasal cyst, and 2 cases of allergic rhinitis. There were 7 cases of major bleeding and 14 cases of minor bleeding according to the degree of bleeding. $\mathrm{POH}$ was detected at the sphenopalatine foramen area in 7 cases, the middle turbinate area in 5 cases, the anterior face of sphenoid sinus in 2 cases, the nasal septum in 2 cases, and other areas in 5 cases (Figure 1a). Four cases with bleeding from the sphenopalatine foramen area and 3 cases from anterior face of sphenoid sinus required revision surgery. Bleeding occurred most commonly 7-10 days after surgery (median time, 7 days); except for one patient, all major bleeding occurred after the 7th postoperative day (Figure $1 \mathrm{~b}$ ).

Surgery for benign tumours, low platelet count, and antithrombotic medication were all independent risk factors for postoperative haemorrhage

We performed univariate analyses of factors affecting $\mathrm{POH}$ by using the chi-square test (Table 2). Sex, BMI, HbA1c, PT, age, blood pressure, operation time, type of anaesthesia, and operating procedure showed no significant association with the incidence of $\mathrm{POH}$. Furthermore, operative procedures for ESS, septoplasty, or submucosal resection of the inferior turbinectomy did not affect the rate of $\mathrm{POH}$.

Factors associated with POH included delayed APTT (14.3\% vs. $2.3 \%, \mathrm{p}<0.01)$, low platelet count $(30.0 \%$ vs. $2.3 \%, \mathrm{p}<0.01)$, anti-thrombotic medication use ( $13.6 \%$ vs. $2.0 \%, \mathrm{p}<0.01)$, and a surgical indication for benign tumours ( $6.3 \%$ vs. $2.2 \%, p=0.03$ ). Based on these results, we further performed a multivariate 
Table 1. Demographics of the cases.

\begin{tabular}{|c|c|c|c|c|}
\hline Characteristics & & Median (range) & $\mathbf{N}$ & $\%$ \\
\hline \multirow[t]{2}{*}{ Sex } & Male & & 499 & $60.6 \%$ \\
\hline & Female & & 308 & $37.4 \%$ \\
\hline Age (median) & (years old) & $57(6-95)$ & & \\
\hline BMI (median) & $\left(\mathrm{kg} / \mathrm{m}^{2}\right)$ & $23.2(14-41.3)$ & & \\
\hline \multirow[t]{2}{*}{ Blood pressure on admission } & Diastolic & $122(76-210)$ & & \\
\hline & Systolic & $74(43-143)$ & & \\
\hline APTT (median) & (sec) & $29(23-127)$ & & \\
\hline PT-INR (median) & & $1.01(0.89-2.78)$ & & \\
\hline Platelet count (median) & $\left(\times 10^{3} / \mu \mathrm{l}\right)$ & $233(22-522)$ & & \\
\hline ESS & & & 651 & $80.7 \%$ \\
\hline Septoplasty & & & 400 & $49.6 \%$ \\
\hline Submucosal resction of inferior turbinate & & & 297 & $36.8 \%$ \\
\hline Draf type 3 & & & 46 & $5.7 \%$ \\
\hline Medication of antithrombotic drugs & & & 44 & $5.5 \%$ \\
\hline \multirow[t]{2}{*}{ Type of anaesthesia } & Local & & 290 & $35.9 \%$ \\
\hline & General & & 517 & $64.1 \%$ \\
\hline Operation time (median) & $(\min )$ & $115(19-440)$ & & \\
\hline \multirow[t]{2}{*}{ Surgical indication } & Tumour & & 80 & $9.9 \%$ \\
\hline & Other than tumour & & 727 & $90.1 \%$ \\
\hline \multirow[t]{2}{*}{ Postoperative haemorrhage } & Minor bleeding & & 14 & $1.7 \%$ \\
\hline & Major bleeding & & 7 & $0.9 \%$ \\
\hline
\end{tabular}

APTT = activated partial thromboplastin time; BMI = body mass index; ESS = endoscopic sinus surgery; $\mathrm{HbA1c}=$ haemoglobin A1c; PT-INR = prothrombin time-international normalized ratio; $\mathrm{OR}=$ odds ratio. Due to incomplete data, we analysed only 457 cases for $\mathrm{HbA} 1 \mathrm{c}$.

a)

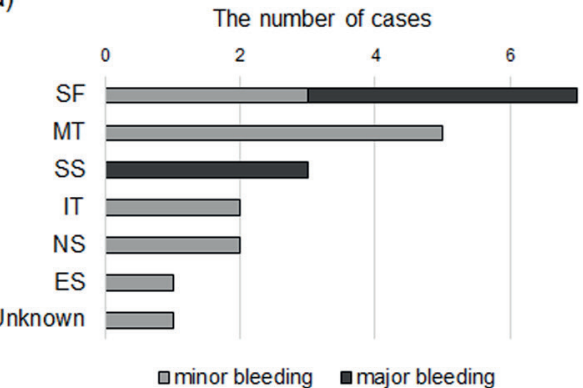

b)

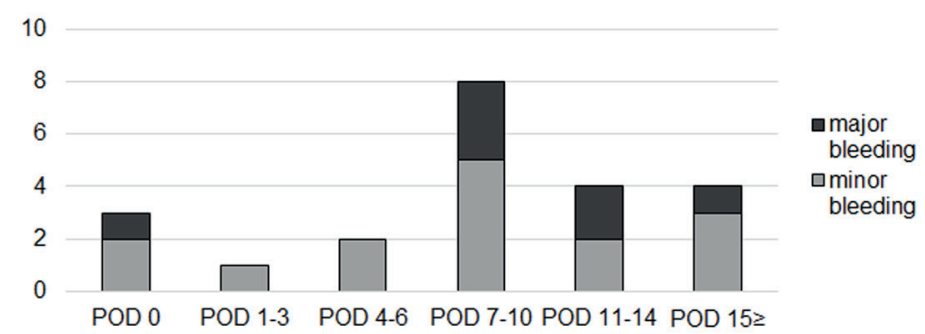

Figure 1. The site and timing of postoperative hemorrhage. a) The site of bleeding. b) The timing of postoperative haemorrhage. SF = sphenopalatine foramen; $\mathrm{MT}=$ middle turbinate; $\mathrm{SS}=$ anterior face of sphenoid sinus; $\mathrm{IT}=$ inferior turbinate; $\mathrm{NS}=$ nasal septum; $\mathrm{ES}=$ ethmoid sinus; $\mathrm{POD}=$ postoperative day.

analysis by logistic analysis. This analysis showed that surgery for benign tumour (odds ratio [OR], 3.11; 95\% Cl, 1.04-9.27), low platelet counts (OR, 16.64; $95 \% \mathrm{Cl}, 2.53-109.41)$, and anti-thrombotic medication (OR, 5.48; 95\% Cl 1.64-18.32) were all independent risk factors for $\mathrm{POH}$ (Table 3 ).

\section{Discussion}

TES is a standard procedure for nasal and sinus disease without malignancy. $\mathrm{POH}$ is one of the most common complications following TES. Previous studies have focused on $\mathrm{POH}$ as a complication, but few reports have studied its risk factors. This is the first study to analyse risk factors for $\mathrm{POH}$ after not only ESS, but also endoscopic nasal surgeries in general. A previous systematic review showed a median $\mathrm{POH}$ rate of $2.5 \%(0.2-21.1 \%)^{(8)}$. Asaka et al. reported that severe intraoperative bleeding (more than $100 \mathrm{ml}$ ) was seen in $2.5 \%$ of cases, and $\mathrm{POH}$ was seen in 
Table 2. Univariate analysis of association between factors enrolled and postoperative haemorrhage.

\begin{tabular}{|c|c|c|c|c|c|c|}
\hline \multirow[t]{2}{*}{ Variables } & \multirow[t]{2}{*}{ Categories } & \multicolumn{3}{|c|}{ Postoperative haemorrhage } & \multirow[t]{2}{*}{ Odds ratio } & \multirow[t]{2}{*}{ P value } \\
\hline & & Yes & No & $\%$ & & \\
\hline \multirow[t]{2}{*}{ Sex } & male & 17 & 482 & $3.4 \%$ & 2.68 & 0.07 \\
\hline & female & 4 & 304 & $1.3 \%$ & & \\
\hline \multirow[t]{2}{*}{ Age } & $\geq 75$ & 3 & 74 & $3.9 \%$ & 1.60 & 0.45 \\
\hline & $<75$ & 18 & 712 & $2.5 \%$ & & \\
\hline \multirow[t]{2}{*}{ BMI } & $\geq 25$ & 5 & 241 & $2.0 \%$ & 0.71 & 0.50 \\
\hline & $<25$ & 16 & 545 & $2.9 \%$ & & \\
\hline \multirow[t]{2}{*}{$\mathrm{HbA} 1 \mathrm{c}$} & $\geq 6.5 \%$ & 3 & 61 & $4.7 \%$ & 1.88 & 0.34 \\
\hline & $<6.5 \%$ & 10 & 383 & $2.5 \%$ & & \\
\hline \multirow[t]{2}{*}{ PT-INR } & $>1.2$ & 1 & 12 & $7.7 \%$ & 3.23 & 0.25 \\
\hline & $\leq 1.2$ & 20 & 774 & $2.5 \%$ & & \\
\hline \multirow[t]{2}{*}{ APTT } & $\geq 39$ & 3 & 18 & $14.3 \%$ & 7.11 & $<0.01$ \\
\hline & $<39$ & 18 & 768 & $2.3 \%$ & & \\
\hline Platelet count & $\leq 100$ & 3 & 7 & $30.0 \%$ & 18.55 & $<0.01$ \\
\hline$(\times 103 / \mu \mathrm{l})$ & $<100$ & 18 & 779 & $2.3 \%$ & & \\
\hline \multirow[t]{2}{*}{ BP (systolic) } & $\geq 140$ & 4 & 123 & $3.1 \%$ & 1.27 & 0.67 \\
\hline & $<140$ & 17 & 663 & $2.5 \%$ & & \\
\hline \multirow[t]{2}{*}{ BP (diastolic) } & $>90$ & 3 & 96 & $3.0 \%$ & 1.20 & 0.78 \\
\hline & $<90$ & 18 & 690 & $2.5 \%$ & & \\
\hline \multirow[t]{2}{*}{ Antithrombotic medication use } & yes & 6 & 38 & $13.6 \%$ & 7.87 & $<0.01$ \\
\hline & no & 15 & 748 & $2.0 \%$ & & \\
\hline \multirow[t]{2}{*}{ Type of anaesthesia } & local & 14 & 503 & $2.7 \%$ & 1.13 & 0.80 \\
\hline & general & 7 & 283 & $2.4 \%$ & & \\
\hline Operation time & $\geq 180$ & 6 & 151 & $3.8 \%$ & 1.68 & 0.28 \\
\hline$(\min )$ & $<180$ & 15 & 635 & $2.3 \%$ & & \\
\hline \multirow[t]{2}{*}{ Surgical indication } & tumour & 5 & 75 & $6.3 \%$ & 2.96 & 0.03 \\
\hline & ex-tumour & 16 & 711 & $2.2 \%$ & & \\
\hline \multirow[t]{2}{*}{ ESS } & yes & 16 & 635 & $2.5 \%$ & 0.76 & 0.81 \\
\hline & no & 5 & 151 & $3.2 \%$ & & \\
\hline \multirow[t]{2}{*}{ Septoplasty } & yes & 8 & 392 & $2.0 \%$ & 0.62 & 0.40 \\
\hline & no & 13 & 394 & $3.2 \%$ & & \\
\hline \multirow[t]{2}{*}{ Submucosal resection of inferior turbinate } & yes & 8 & 289 & $2.7 \%$ & 1.06 & 0.92 \\
\hline & no & 13 & 497 & $2.6 \%$ & & \\
\hline \multirow[t]{2}{*}{ Draf type 3} & yes & 1 & 47 & $2.1 \%$ & 0.79 & 0.82 \\
\hline & no & 20 & 739 & $2.6 \%$ & & \\
\hline
\end{tabular}

APTT = activated partial thromboplastin time; $\mathrm{BMI}=$ body mass index; $\mathrm{BP}=$ blood pressure; $\mathrm{ESS}=$ endoscopic sinus surgery; $\mathrm{HbA} 1 \mathrm{c}=$ haemoglobin A1c; PT-INR = prothrombin time-international normalized ratio

$0.7 \%$ of cases $^{(15)}$. Among the 3,128 patients undergoing ESS for chronic rhinosinusitis or nasal polyposis, excessive perioperative bleeding was observed in $5.0 \%$, and $\mathrm{POH}$ requiring treatment was observed in $0.8 \%$ of the cases, and half of them required a return to the operating room for haemostasis ${ }^{(16)}$. Suzuki et al. analysed a nationwide Japanese inpatient database and reported postoperative complications of hematoma (0.09\%), blood transfusion $(0.1 \%)$, and $\mathrm{POH}(0.18 \%)$ in 50,734 Japanese patients undergoing ESS for chronic rhinosinusitis treatment ${ }^{(17)}$. Our results showed a higher frequency of $\mathrm{POH}$ than those from this Japanese database, but this could be because our institution is a tertiary care institution and we may have had more 
Table 3. Multivariate analysis of factors associated with postoperative haemorrhage.

\begin{tabular}{|lcccc|}
\hline Variables & $\begin{array}{c}\text { Odds } \\
\text { ratio }\end{array}$ & $\begin{array}{c}95 \% \mathrm{Cl} \\
\text { lower }\end{array}$ & $\begin{array}{c}95 \% \mathrm{Cl} \\
\text { upper }\end{array}$ & P value \\
\hline $\begin{array}{l}\text { Surgical indication, } \\
\text { tumour vs. non-tumour }\end{array}$ & 3.11 & 1.04 & 9.27 & 0.04 \\
$\begin{array}{l}\text { Platelet count }\left(\times 10^{3} / \mu \mathrm{l}\right), \\
\geq 100 \text { vs }<100\end{array}$ & 16.64 & 2.53 & 109.41 & $<0.01$ \\
\hline $\begin{array}{l}\text { Anti-thrombotic drugs, } \\
\text { yes vs no }\end{array}$ & 5.48 & 1.64 & 18.32 & $<0.01$ \\
\hline
\end{tabular}

$\mathrm{Cl}=$ confidence interval

severe cases. Ramakrishnan et al. showed that the percentage of patients with haemorrhage requiring transfusion was $0.76 \%{ }^{(18)}$. In previous reports, the frequency of $\mathrm{POH}$ had varied, possibly because of differences in the operative procedure, surgical indications, and definition of $\mathrm{POH}$. In this study, we included all the patients who underwent any kind of treatment after the end of the surgery. In a previous systematic review, 2.2\% (1.2-4.6\%) of cases required gauze packing or hospitalization, which was comparable to our results ${ }^{(8)}$.

There have been few previous reports of $\mathrm{POH}$ following nasal surgery. The rate of $\mathrm{POH}$ associated with septoplasty was reported to be approximately the same as that of ESS, ranging from $0.8-3.0 \%{ }^{(9-11)}$, and this figure was similar in our study. Common areas of postoperative nasal bleeding were related to the sphenopalatine artery region. At least 10 cases (47.1\%) with $\mathrm{POH}$ at the sphenopalatine foramen and anterior face of the sphenoid sinus were considered to have bleeding originating from the sphenopalatine artery. All cases requiring haemostasis surgery was related to the sphenopalatine artery. In cases posterior bleeding, it is difficult to identify the source of bleeding; in such cases, it is preferable to perform the procedure in the operating room using an endoscope ${ }^{(19,20)}$.

The second most common $\mathrm{POH}$ occurred in the middle turbinate, and that may have been caused by partial resection of the middle turbinate during ESS. Reduction of the middle turbinate was performed with the aim of improving ventilation to the middle meatus and olfactory cleft ${ }^{(21)}$. While middle turbinate resection did not increase the risk of major $\mathrm{POH}$, minor bleeding has been reported to be significantly increased, particularly if the patient was on anticoagulants ${ }^{(22)}$. The frequency of bleeding from the middle turbinate was high; however, none of the cases in our study required revision surgery. These results suggest that the bleeding from the middle turbinate was easy to stop. To prevent $\mathrm{POH}$, cauterizing the edge of the mucosa and avoiding turbinate bone exposure are important.

The median time of $\mathrm{POH}$ occurrence was 7 days after surgery. Most of the major bleeding cases occurred after the 7th postoperative day. Usually, patients are discharged by the 7th po- stoperative day. Therefore, it is necessary to inform the patient in advance that there is a risk of bleeding after discharge. The delayed postoperative haemorrhage may be explained by the process of wound healing, which is divided into three phases: the inflammation phase, proliferation (new tissue formation) phase, and remodelling phase ${ }^{(23,24)}$. The inflammation phase lasts up to 48 hours after injury and has a hypoxic or ischemic environment in which fibrin masses are formed. The proliferation stage lasts 48 hours to 10 days. During this period, a crust is formed, and neovascularization appears. Increased blood flow through capillaries along with fibroblasts and macrophages replaces the fibrin matrix with granulation tissue.

In our study, the three cases of bleeding on the day of surgery were thought to be caused by inadequate haemostasis during the operation. In contrast, late onset haemorrhage was thought to occur in the proliferation phase of wound healing. Experiments involving tonsillectomy in mice have shown that the crust was removed followed by exposure of neovascularization during the proliferation phase ${ }^{(25)}$. The reason for the high frequency of $\mathrm{POH}$ in the proliferation phase after TES could be active neovascularization and the loss of crusting by nasal washing. There were eight cases with $\mathrm{POH}$ after 11 days postoperatively, and this complication seemed to occur due to delayed wound healing by infection. Several reports reported asthma, presence of nasal polyps, symptom severity, health-related quality of life, the polyp score, and the Lund-Mackay score as risk factors for major complications in $\mathrm{ESS}^{(16)}$. Many reports have examined intraoperative bleeding in ESS, but none have examined the risk factors for $\mathrm{POH}$ in detail. Siedek et al. examined the correlation between the experience of surgeons and both intraoperative and $\mathrm{POH}^{(26)}$. Interestingly, the $\mathrm{POH}$ rates encountered by surgeons with 5-6 years of experience were significantly greater than those of surgeons with $0-4$ years of experience or surgeons with $>6$ years of experience.

In the present study, multivariate analysis revealed that antithrombotic medication, low platelet counts, and benign tumour surgery were all independent risk factors for $\mathrm{POH}$. Antithrombotic medication and low platelet counts directly impact haemostatic function. The number of patients taking anticoagulant medication worldwide is increasing, and several guidelines have been developed for their management ${ }^{(27)}$. However, the perioperative use of antithrombotic agents for ESS has not been well studied. A retrospective case control study indicated that ESS is a safe procedure when performed in patients receiving anticoagulation or antiplatelet therapy and suggests that ESS could be classified as a type of surgery with moderate bleeding risk $^{(28)}$. It is difficult to weigh the risk of thromboembolism due to the withdrawal of medication during the perioperative period as well as the risk of haemorrhage due to continued use. It is now strongly recommended to develop original guidelines and policies for handling of anti-thrombotic drugs during surgical 
procedures in all facilities ${ }^{(29,30)}$.

Regarding platelet count, only 10 patients had a low platelet count $(<100,000 / \mu \mathrm{l})$, but three had $\mathrm{POH}$. Therefore, low platelet count was considered to be a risk factor for $\mathrm{POH}$. The Cochrane library notes that low platelet counts increase the risk of bleeding, but there is insufficient evidence that platelet transfusions reduce $\mathrm{POH}$ or all-cause mortality ${ }^{(31)}$. At present, one should consider platelet transfusion using judgement based on individual clinical experience and expertise. In our institution, all patients were treated with NSAIDs without opioids after surgery. NSAIDs impair platelet function and may make bleeding more likely. However, Moeller et al. conducted a randomised trial of ketorolac and compared it to fentanyl, evaluating the analgesic effect and postoperative bleeding ${ }^{(32)}$. The study found no difference in analgesia or postoperative bleeding between the two groups and concluded that ketorolac is a safe analgesic that can be used after TES. A state of the art review indicated that the clinical impact on perioperative bleeding is low ${ }^{(33)}$. In this study, the use of NSAIDs could not be considered a risk factor for postoperative bleeding because NSAIDs were used in all patients.

The significantly higher risk of $\mathrm{POH}$ in patients with benign tumours could be attributed to two reasons. First, the range of bone exposure during surgery for the tumour is more extensive compared to normal sinusitis surgery. Second, the feeding artery of the tumour may not be properly cauterized. If the artery originates in the bone, it may be difficult to cauterize sufficiently. In recent years, the indications for ESS have expanded for a variety of paranasal tumours; for example, inverted papillomas ${ }^{(4)}$ and almost all benign tumours in our institution are operated on endoscopically. Careful cauterization or ligation of feeding arteries is thought to reduce $\mathrm{POH}$.

This study had several limitations. First, it was a single-centre retrospective study. Second, anti-thrombotic drugs were discontinued preoperatively in most cases, but the timing of resumption after surgery varied. We did not separate anticoagulants and antiplatelet agents for the purposes of analysis. Third, the treatment for $\mathrm{POH}$ was not well established and varied between physicians. The physician could have chosen the treatment in the operating room, even if it was not necessary. Therefore, all cases of $\mathrm{POH}$, whether treated in the operating room or not, were analysed. A shorter duration of treatment can be achieved in patients with initial cauterisation for epistaxis compared with other treatments ${ }^{(34)}$. However, it is necessary to identify the bleeding site for the cauterisation and it is difficult to find a haemostatic point in the situation of severe bleeding. Systematic endoscopic assessment (SEA) has been proposed as an observation method to make it easy to find the bleeding site(35). In SEA, active bleeding is stopped with gauze packing, followed by observation with a rigid scope under general anaesthesia in a defined order to identify bleeding sites. In our institution, observation and haemostasis methods for postoperative bleeding were not unified, so in some cases, gauze packing was chosen without identifying the bleeding point. It is necessary to devise a routine observation method for postoperative bleeding based on the data of the bleeding point of this study. In addition, it was considered necessary to aim for a short treatment period by cauterisation treatment when the bleeding point was identified.

\section{Conclusions}

Postoperative haemorrhage following endoscopic nasal sinus surgery occurred in $2.7 \%$ of patients. Treatment in the operating room for $\mathrm{POH}$ was required in $0.9 \%$ of the cases. The majority of haemorrhages occurred after the 7th postoperative day. The independent risk factors for $\mathrm{POH}$ were surgery for the tumour, low platelet counts, and antithrombotic medication use. In patients with these factors, extra care is needed with haemostasis.

\section{Acknowledgments}

We would like to thank Editage (www.editage.com) for English language editing. This work was supported by JSPS KAKENHI Grant (no. 19K09890). and a Grant-in-Aid from the Japan Agency for Medical Research and Development (no. 19ek0410050h0002).

\section{Authorship contribution}

$\mathrm{HI}$ and $\mathrm{MH}$ supervised the project. $\mathrm{KA}, \mathrm{HA}, \mathrm{TT}, \mathrm{YM}$, and $\mathrm{MH}$ analysed the data and wrote the manuscript. $\mathrm{KA}, \mathrm{MH}, \mathrm{HA}, \mathrm{TT}, \mathrm{KT}$, and $Y M$ recruited and clinically characterized patients. $K A, M H$, $\mathrm{HA}, \mathrm{AN}$, SO, YM, and KT provided advice on project planning and data interpretation. All authors participated in discussion of the results and critically polished and approved the final draft.

\section{Conflict of interest}

The authors declare that there is no conflict of interest.

\section{Ethics approval}

This report was approved by the Institutional Review Board of Osaka University Hospital.

\section{Consent for publication}

Not applicable.

\section{Availability of data and materials}

The datasets used and/or analysed during the current study are available from the corresponding author on reasonable request.

\section{Abbreviations}

TES: transnasal endoscopic surgery; $\mathrm{POH}$ : post-operative hemorrhage; ESS: endoscopic sinus surgery; BMI: body mass index; HbA1c: haemoglobin A1c; APTT: activated partial thromboplastin time; PT-INR: prothrombin time/international normalized ratio; OR: odds ratio. 


\section{References}

1. Orlandi RR, Kingdom TT, Hwang PH, et al. International Consensus Statement on Allergy and Rhinology: Rhinosinusitis. Int Forum Allergy Rhinol 2016; 6: S22-209.

2. Fokkens WJ, Lund VJ, Hopkins C, et al. European position paper on rhinosinusitis and nasal polyps 2020. Rhinology 2020; 58: 1-464.

3. Champagne C, Ballivet de Régloix S, Genestier L, Crambert A, Maurin O, Pons Y. Endoscopic vs. conventional septoplasty: A review of the literature. Eur Ann Otorhinolaryngol Head Neck Dis 2016; 133: 43-46.

4. Lisan Q, Laccourreye O, Bonfils P. Sinonasal inverted papilloma: From diagnosis to treatment. Eur Ann Otorhinolaryngol Head Neck Dis 2016: 133: 337-341.

5. Nagalingeswaran A, Kumar RD. Newer surgical options for nasal allergy. Indian J Otolaryngol Head Neck Surg 2020; 72: 133-139.

6. Scangas GA, Gudis DA, Kennedy DW. The natural history and clinical characteristics of paranasal sinus mucoceles: a clinical review. Int Forum Allergy Rhinol 2013; 3: 712-717.

7. Stankiewicz JA, Lal D, Connor M, Welch K. Complications in endoscopic sinus surgery for chronic rhinosinusitis: A 25-year experience. Laryngoscope 2011; 121: 2684-2701.

8. Dalziel K, Stein K, Round A, Garside R, Royle P. Endoscopic sinus surgery for the excision of nasal polyps: A systematic review of safety and effectiveness. Am J Rhinol 2006 20: 506-519.

9. Mutlu V, Kaya Z. Comparison of the effect of the lidocaine, tetracaine, and articaine application into nasal packs on pain and haemorrhage after septoplasty. Eur Arch Otorhinolaryngol 2018; 275: 2481-2485.

10. Garzaro M, Dell'Era V, Brucoli M, Boffano P Benech A, Aluffi Valletti P. Endoscopic septoplasty as a routine approach: Our experience on 647 patients. J Craniomaxillofac Surg 2019; 47: 1530-1534.

11. Sohail Awan M, lqbal M. Nasal packing after septoplasty: A randomized comparison of packing versus no packing in 88 patients. Ear Nose Throat J 2008; 87: 624-627.

12. Kim DH, Kim S, Kang H, Jin HJ, Hwang SH. Efficacy of tranexamic acid on operative bleeding in endoscopic sinus surgery: A meta-analysis and systematic review. Laryngoscope 2019; 129: 800-807.

13. Jahanshahi J, Tayebi E, Hashemian F Bakhshaei MH, Ahmadi MS, Seif Rabiei MA Effect of local desmopressin administration on intraoperative blood loss and quality of the surgical field during functional endoscopic sinus surgery in patients with chronic rhinosinusitis: a triple-blinded clinical trial. Eur Arch Otorhinolaryngol 2019; 276: 1995-1999.
14. Liu W, Jiang $H, P u H$, Hu D, Zhang Y. The effect of magnesium sulfate on surgical field during endoscopic sinus surgery: A meta-analysis of randomized controlled trials. Medicine (Baltimore) 2019; 98: e16115.

15. Asaka D, Nakayama T, Hama T, et al. Risk factors for complications of endoscopic sinus surgery for chronic rhinosinusitis. Am J Rhinol Allergy 2012; 26: 61-64.

16. Hopkins C, Browne JP, Slack R, et al. Complications of surgery for nasal polyposis and chronic rhinosinusitis: The results of a national audit in England and Wales. Laryngoscope 2006; 116: 1494-1499.

17. Suzuki S, Yasunaga $H$, Matsui H, Fushimi K, Kondo K, Yamasoba T. Complication rates after functional endoscopic sinus surgery: Analysis of 50,734 Japanese patients. Laryngoscope 2015; 125: 1785-1791.

18. Ramakrishnan VR, Kingdom TT, Nayak J V., Hwang PH, Orlandi RR. Nationwide incidence of major complications in endoscopic sinus surgery. Int Forum Allergy Rhinol 2012; 2: 34-39.

19. Meccariello G, Georgalas C, Montevecchi F et al. Management of idiopathic epistaxis in adults: What's new? Acta Otorhinolaryngol Ital 2019; 39: 211-219.

20. McClurg SW, Carrau R. Endoscopic management of posterior epistaxis: a review. Acta Otorhinolaryngol Ital 2014; 34: 1-8.

21. Daramola OO, Chandra RK. Chronic rhinosinusitis and endoscopic sinus surgery. World J Otorhinolaryngol Head Neck Surg 2018;4: 29-32.

22. Miller AJ, Bobian M, Peterson E, Deeb R. Bleeding risk associated with resection of the middle turbinate during functional endoscopic sinus surgery. Am J Rhinol Allergy 2016; 30: 140-142

23. Reinke JM, Sorg H. Wound repair and regeneration. Eur Surg Res. 2012;49(1):35-43.

24. Gurtner GC, Werner S, Barrandon Y, Longaker MT. Wound repair and regeneration. Nature 2008; 453: 314-321.

25. Beswick DM, Santa Maria C, Ayoub NF Capasso R, Santa Maria PL. Epithelial separation theory for post-tonsillectomy secondary hemorrhage: evidence in a mouse model and potential heparin-binding epidermal growth factor-like growth factor therapy. Eur Arch Otorhinolaryngol 2018; 275: 569-578.

26. Siedek V, Pilzweger E, Betz C, Berghaus A, Leunig A. Complications in endonasal sinus surgery: A 5-year retrospective study of 2,596 patients. Eur Arch Otorhinolaryngol 2013; 270: 141-148.

27. Dubois V, Dincq AS, Douxfils J, et al. Perioperative management of patients on direct oral anticoagulants. Thromb J 2017 ; 15: 1-17.

28. Sargi Z, Casiano R. Endoscopic sinus surgery in patients receiving anticoagulant or antiplatelet therapyy. Am J Rhinol 2007; 21: 335-338.

29. Heidbuchel $H$, Verhamme $P$, Alings $M$, et al. Updated European Heart Rhythm Association Practical Guide on the use of non-Vitamin $\mathrm{K}$ antagonist anticoagulants in patients with non-valvular atrial fibrillation. Europace 2015; 17: 1467-1507

30. Faraoni D, Levy JH, Albaladejo P, et al Updates in the perioperative and emergency management of non-vitamin K antagonist oral anticoagulants. Crit Care 2015; 19 . $1-6$

31. Estcourt LJ, Malouf R, Doree C, Trivella M, Hopewell S, Birchall J. Prophylactic platelet transfusions prior to surgery for people with a low platelet count. Cochrane Database Syst Rev 2018; 2018: CD012779.

32. Moeller C, Pawlowski J, Pappas AL, Fargo K, Welch K. The safety and efficacy of intravenous ketorolac in patients undergoing primary endoscopic sinus surgery: a randomized, double-blinded clinical trial. Int Forum Allergy Rhinol 2012; 2:342-347.

33. Cramer JD, Barnett ML, Anne S, et al. Nonopioid, Multimodal Analgesia as First-line Therapy After Otolaryngology Operations: Primer on Nonsteroidal Anti-inflammatory Drugs (NSAIDs). Otolaryngol Head Neck Surg 2020 Aug 18: 194599820947013. Epub ahead of print.

34. INTEGRATE (UK National ENT research trainee network) on its behalf; Mehta N, Stevens K, et al. National prospective observational study of inpatient management of adults with epistaxis - a National Trainee Research Collaborative delivered investigation. Rhinology 2019; 57:180-189.

35. Loures CN, Castro TC, Luz Matsumoto GR, et al. Systematic endoscopic assessment of bleeding sites in severe epistaxis: the role of the S-point and the superior epistaxis. Rhinology. 2020 May 5. Epub ahead of print.

\author{
Masaki Hayama MD PhD \\ Assistant Professor \\ Department of Otorhinolaryngology \\ Head and Neck Surgery \\ Osaka University Graduate School of \\ Medicine \\ 2-2 Yamada-oka, Suita \\ Osaka 565-0871, Japan
}

Tel: +81-6-6879-3951

Fax: +81-6-6879-3959

E-mail:

mhayama@ent.med.osaka-u.ac.jp

ISSN: 2589-5613 / @2020 The Author(s). This work is licensed under a Creative Commons Attribution 4.0 International License. The images or other third party material in this article are included in the article's Creative Commons license, unless indicated otherwise in the credit line; if the material is not included under the Creative Commons license, users will need to obtain permission from the license holder to reproduce the material. To view a copy of this license, visit http://creativecommons.org/licenses/by/4.0/ 